\title{
The effectiveness of technology based (interactive) distance learning methods in a large South African financial services organisation
}

\author{
M. van der Spuy and A. Wöcke* \\ Gordon Institute of Business Science, University of Pretoria, \\ PO Box 787602, Sandton 2146, Republic of South Africa \\ wockea@gibs.co.za \\ Received April 2003
}

\begin{abstract}
The trend towards technology-based learning (or 'e-learning') is increasing, driven largely by anecdotal evidence of advantages. This article compares the effectiveness of the technology supported learner driven distance learning methods to the 'traditional' classroom based teaching model and the simulation model. The results of the training methods on a sample of cashiers in a major South African bank are compared and the study finds that there were significant differences between the outcomes of three methods of training that had an impact on performance and knowledge retention with classroom based learning having the greatest impact.
\end{abstract}

*To whom all correspondence should be addressed.

\section{Introduction}

Management and Learning and Development professionals have been faced with a number of challenges regarding the training and development of staff and have turned to technology based and assisted training solutions. The effectiveness of these solutions has been evaluated by their ability to meet current business challenges, which include:

- Increased numbers of employees to train;

- Increased complexity in the type of work employees are required to perform (and the tools used at work);

- Pressure on employees to learn and demonstrate new competencies faster and at a higher level;

- Fast change in the business environment and less funding to achieve all the above

These challenges have largely been responsible for the growth of technology-supported learning as managers turned to technology for solutions to new problems.

\section{Definitions}

The technological advances supporting learning have and continue to occur rapidly making it difficult for researchers and the literature to stay abreast of the changes and emergence of new terminology. Thus, it is important to clarify and define the terminology used in this research to ensure a common understanding. The term technology based (interactive) distance learning (TBDL) will be used to describe the method of instruction which combines advances in technology, adult learning theory and facilitation in the learning and development processes. This term will be used throughout the article to describe integrated technology supported learning processes in all of their forms.

\section{Advantages of technology based distance learning}

Exploiting the advances in technology has become an imperative for companies - cost pressures, smaller training departments, shorter product life cycle times, impact of employee travelling costs and time away from work all mitigate in favour of the use of technology (Bassi, Benson \& Cheney, 1996). Research reported by Carozza (2000), Chamberlain (1997), Galagan (2000), and Hamel (2000) indicate that embedded support systems, computer-based training, multimedia training via the Internet and intranet form part of 'channels' for training delivery and not strategies as initially proposed. The implication is that companies should not build a strategy around a delivery channel, but around the broader concept of technology enabled distance learning.

A study published by Forbes Magazine (15 December 2000) of 11 multinational firms, which include inter alia Cisco Systems, IBM, Dell Computers, Shell and Unipart, reveals that technology assisted learning reduced costs and length of training time. The study indicated that comparatively, over three years, the total cost of training was reduced from $\$ 3,3 \mathrm{~m}$ to $\$ 1,7 \mathrm{~m}$. The cost per learner decreased from $\$ 760$ to $\$ 106$ over a five year period and the number of training hours of a sample lecture/lab course was reduced by $60 \%$ from 28 hours to 11,2 hours when converted to technology supported learning 


\section{The growth in technology based (interactive) distance learning methods}

Due to the substantial initial costs associated with using TBDL methods, the return on investment is not immediately apparent and firms rather use TBDL solutions to remain competitive and maintain a skilled workforce. Eager (1999) identified one major benefit of TBDL as affording large numbers of employees access to ongoing quality training programmes.

The use of technology-based training continues to increase worldwide with wider adoption as technology deals with problems such as bandwidth limitations, technology costs and quality of content (Eager, 1999).

Significant growth is forecasted for TBDL methods; the global on-line learning business (TBDL) will approach $\$ 22$ bn by 2003. The European TBDL market alone, is expected to grow to $\$ 4$ bn by 2004 , representing a compound annual growth rate of $96 \%$ over 5 years. Technology-based training in countries lagging the current growth trend will accelerate their investment; for example, companies in France are expected to increase TBDL in their training budgets from $2 \%$ in 2000 to 12 percent in 2001 (Jouvancy, 2001).

At the core of the technological development of learning systems is the convergence of the once distinct media (or channel) such as image, sound, written documentation and computer networks into digital multimedia. In addition Learning Theory is being combined with computer, television, satellite, fibre-optic and microchip technologies. This creates a vast interactive communications and information network (which also provides the link with knowledge management, Egan \& Kim, 2000) that places expertise more in the network and less in the person. A number of limitations of technology supported learning systems exist, specifically in the South African context. These are accessibility to fixed line bandwidth and satellite bandwidth, access to quality content, and limited customisation of learning management systems for the South African context.

\section{The study}

The study was conducted in a South African financial services company. Skills training takes place at various levels throughout the organisation, but is concentrated at the clerical and supervisory levels. Following a major restructuring of the business, it was decided to adopt a technology based training solution as the preferred delivery channel in the non-metro areas to overcome the obstacle of huge distances between points of representation. An interactive satellite system was chosen as the core technology and delivery channel. Learning programmes were converted to be compatible with this medium.

\section{Training programmes for comparison}

The decision regarding which training programme to use in the investigation was a critical component in planning the study. Two conflicting objectives had to be satisfied: on the one hand, in order to generalise the findings, the programme selected must conform to the following criteria:

- It must be critical to the success of the organisation;

- It must have a high utilisation rate;

- It must comprise the training of technical, risk and behavioural components - thus similar to and representative of most of the training needs in the firm.

On the other hand, the work role and associated training programme selected must be sufficiently independent and different from others to minimise the impact of extraneous or confounding variables which could have an impact on the results, such as prior learning, transfer of knowledge from one role to another, etc. Thus, after having considered the subject matter and the learning needs, the environment in which the learning occurs, the audience being targeted with the training, and the impact on the organisation, the role of a cashier was chosen.

This role, although classified as a clerical role, is a highly complex one that demands concentration, alertness and skill (counting money, taking deposits, paying out cash, performing multiple procedures and checks). Most of these demands are made on the incumbent simultaneously. To be rated as a competent cashier requires an in-depth knowledge of processes and procedures. It further requires appropriate behaviours such as customer service skills. Finally, success, which is defined as 'balancing the debit and credit transactions at the end of the day' requires 100 percent accuracy in all activities performed.

The Learning and Development department presents three different cashier training programmes, traditional classroom-based training, experiential learning, and technology based distance learning.

\section{Traditional classroom-based training programme}

This programme has a three-day duration.

Three content areas covered are:

- 'deposit' related activities;

- 'encashment' related activities; and

- $\quad$ rules, regulations and procedures.

Only theoretical concepts and constructs are covered during the programme. Practical exposure is given after the training programme in an unstructured manner in the workplace.

\section{Experiential learning programme.}

The programme is conducted over five days. The learning material content is similar to that of the traditional classroom-training programme described above. However, 
training takes place at a 'cashier school' which uses real cash and role-plays to simulate the real business environment. In addition, customer interaction, difficult scenarios and high-risk activities are simulated and practised.

\section{Technology based distance learning course.}

The course is run over two days and consists of:

- $\quad$ Pre-course study material (in this case, because of cost and other factors, delivered in an asynchronous, paperbased format).

- Interpretation and reflection. Basic principles, important learning points, and best practice tips (covered in the pre-course material) are discussed in a live interactive satellite broadcast (video and sound/ text). Learners in remote sites can discuss issues that are unclear to them and learn from each other (in this virtual classroom).

- During off-line sessions, an on-site coach (typically an experienced job incumbent) shows the learner how these concepts should be applied on the job.

- At the end of the two day facilitated session, the learner is required to study the theoretical concepts and undergo a formal evaluation.

Following the course, the learner is allowed to work with the on-site coach to practice the new skills.

\section{The sample}

The entire population of employees trained as cashiers over a six-month period was used in the study. The statistical requirements of sampling design and sample size (Johnson \& Wichern, 1997) were compromised in that subjects were not randomly assigned to the three programmes. The allocation was done on the basis of geographic location of the delegates and on the availability of facilitators to present courses. It is acknowledged that confounding variables, such as geographic location, quality of candidates (age, skills, qualifications) and skills of facilitators - both course and onsite facilitators - could have impacted on the results of the study and that these may have reduced the generalisability of the results to other settings, but not greatly (Johnson \& Wichern, 1997).

Table 1: Initial sample composition

\begin{tabular}{|c|c|c|c|c|}
\hline $\begin{array}{c}\text { Sample } \\
\text { description }\end{array}$ & Total & Tbdl & $\begin{array}{c}\text { Classroom \& } \\
\text { simulation }\end{array}$ & Classroom \\
\hline $\mathrm{N}$ & 140 & 71 & 22 & 47 \\
\hline Attrition $^{1)}$ & 30 & 21 & 1 & 8 \\
\hline Final $n$ & 110 & 50 & 21 & 34 \\
\hline
\end{tabular}

${ }^{1)}$ Attrition is defined as employees no longer performing cashier duties after three months for any reason. Most frequently cited reasons were (in descending order): resignations, dismissals, change in duties, availing of maternity leave and stress.
Employees who were no longer performing cashier duties up to and including three months after the initial training are excluded from the final sample (attrition). The higher attrition rate observed in the TBDL group is as a result of the geographic distribution of the employees. A much higher attrition rate is observed among rural recruits across all functions because once hired and trained, they resign and move to the urban areas in search of better prospects.

Although a review of the biographical details of the sample group could have been useful in identifying confounding variables, this information was deemed not relevant to this study. The reason is that the entire population of trainee cashiers was used which comprise all the individuals who have met the basic selection criteria (suitability for the role). Once selected, these individuals require training, irrespective of their background, ability, personality, etc. Further, the aim of this investigation is not to measure or improve on the effectiveness of selection, but to determine the extent to which the three different training mediums were effective in facilitating employee competence.

\section{Criteria used to measure effectiveness of learning}

A cash flow and capital investment analysis was conducted prior to the purchase of the Interactive Satellite System (utilised in the TBDL course), which indicated that it would yield savings from year 2 . Thus, having passed the financial hurdle imposed on capital expenditure the study has shifted its focus from the financial or cost saving criteria to performance-related criteria. The remaining criteria are focused on performance improvement factors such as supervisor and other ratings of performance, knowledge retention and transfer.

In deciding upon criteria for comparison, three principles were used: relevance, sensitivity and practicality (Akkerman, 1989).

- Relevance - is the outcome as measured by the criterion relevant to the overall research design?

- Sensitivity - are measures of success (criteria) sufficiently sensitive to discriminate between successful and unsuccessful candidates.

- Practicality - are the measures of success easily obtainable with a high accuracy or are they subjective and open to interpretation?

Landy and Rastegary (1989) identify a number of ancillary measures that may be used as criteria. These include absences, turnover, accidents, knowledge tests, and handson measures (criterion work-sample tests).

Measures from three of these categories are used in the study. These are

- $\quad$ supervisory ratings; 
- $\quad$ objective measure of performance (absolute value of differences in cashiers' cash); and

- $\quad$ ancillary measures - specifically knowledge tests both immediately after training and one three months later.

These categories were considered to be the most relevant to this particular investigation.

\section{Supervisory ratings}

To improve the reliability of supervisory ratings, a ten point behaviourally anchored rating scale was developed and applied (Smith \& Kendall, 1963). Two sets of supervisory ratings were obtained. First, immediately after the learning intervention took place, and the second set, three months after the training programme.

\section{Immediately after learning intervention}

Supervisory ratings were obtained on 2 criteria

- balancing transactions at the end of the day without assistance and

- $\quad$ cash handling ability.

\section{Three months after learning intervention}

Supervisory ratings were obtained on the following criteria

- deposit taking skills;

- $\quad$ encashments skills;

- $\quad$ procedures and rules (knowledge and application); and

- $\quad$ general independent functioning (limited referrals for guidance/ assistance).

The two sets of supervisory rating obtained are not exactly the same because it is not feasible to obtain detailed ratings before employees have had the opportunity to internalise the learning and practice the skills and this is dealt within an examination. The three detailed ratings in the second set of criteria (deposit taking skills, encashments skills, procedures and rules) are equivalent to 'cash handling ability' in the first set). Similarly, independent functioning in the second set is equivalent (although broader) to 'balancing transactions without assistance' in the first set.

This set of criteria was included to verify claims in the literature of increased performance ratings attained by staff who have attended a technology based distance learning programme (as a result of better performance).

\section{Tests of competence}

Two sets of data were obtained. First, a post-course theoretical examination covering the entire curriculum was held. The second set of data was obtained from a second theoretical examination conducted three months after the training course was completed. The second examination comprised four components. These components were

- deposit taking; and

- encashments;

- $\quad$ rules and procedures; and

- $\quad$ general knowledge.

This group of criteria was included in order to verify specific areas of increased knowledge retention.

\section{Objective performance measures}

Again, two sets of measures were obtained. The first measure was the sum of differences in cashiers' cash in the first month (both surplus and short). The second measure was similar - the sum of differences in cashiers' cash in the third month after having attended the cashier training programme.

The underlying assumption in using this measure is that the accuracy with which staff perform their duties should be directly related to their level of competence. Thus highly competent staff should make fewer errors - and in this instance errors are expressed as either a deficit (shortage) or surplus.

It is acknowledged that other extraneous variables might have had an influence on the absolute value of cashiers' inability to balance debit and credit transactions over a period of one month. For example, fraud syndicates operating in certain areas, varying volumes between different areas affecting the results of particular staff members (a direct correlation exists between the volume of transactions processed and the number of errors made), etc. Although these arguments may to some extent hold true, the counter argument is equally true - that well trained staff will be equipped to deal with these challenges, and if these influences were present, that it would be randomly distributed across the three groups.

\section{Design of the investigation}

Three groups were constructed:

- Learners that attended the traditional classroom-based course.

- Learners that attended the classroom and simulation based course.

- Learners that participated in the technology supported distance learning cashiers course.

Learners were assigned to a course. Fewer classroom-based programmes were scheduled over the 3-month period. Only two classroom and simulation based programmes were presented as a result of resource constraints (cashier school 
and facilitator availability). This resulted in 71 staff attending the TBDL programme, 47 the classroom course, and 22 the classroom and simulation programme.

Learners from each course were evaluated immediately after they have completed a training course. Supervisors completed the supervisory evaluation sheet after having observed the staff member's performance.

A further theoretical examination was distributed to all delegates three months after the initial training to measure knowledge retention. Supervisors were requested to oversee the completion of this examination. The Rand value of differences in cashiers' cash was obtained from the company's operating system to minimise errors.

\section{Formulation of hypotheses}

The following hypotheses were formulated:

The overall hypothesis was stated in testable form as:

$\mathrm{H}_{0}$ : No significant differences in mean scores on the selected criteria exist between classroom-based cashier training, classroom-based and simulation cashier training, and technology based distance learning cashier-training programmes.

$\mathrm{H}_{1}$ : Significant differences in mean scores exist between classroom-based cashier training, classroom-based and simulation cashier training, and technology based distance learning cashier-training programmes.

Because three groups of criteria were identified it was decided to formulate further hypotheses to investigate specific sub-groups in the sample. The following subhypotheses were formulated:

\section{Sub-hypothesis 1}

$\mathrm{H}_{0}$ : For supervisory ratings, no significant differences in mean scores exist between classroom-based cashier training, classroom-based and simulation cashier training, and technology based distance learning cashier-training programmes

$\mathrm{H}_{1}$ : For supervisory ratings, significant differences in means exists between classroom-based cashier training, classroom-based and simulation cashier training, and technology based distance learning cashier training programmes

\section{Sub-Hypothesis 2}

$\mathrm{H}_{1}$ : For objective performance ratings, no significant differences in mean scores exist between classroombased cashier training, classroom-based and simulation cashier training, and technology based distance learning cashier training programmes.

$\mathrm{H}_{1}$ : For objective performance ratings, significant differences in means exist between classroom-based cashier training, classroom-based and simulation cashier training, and technology based distance learning cashier-training programmes. 


\section{Sub-Hypothesis 3}

$\mathrm{H}_{0}$ : For scores achieved on competence tests, no significant differences in mean scores exist between classroombased cashier training, classroom-based and simulation cashier training, and technology based distance learning cashier training programmes

$\mathrm{H}_{1}$ : For scores achieved on competence tests significant differences in means exist between classroom-based cashier training, classroom-based and simulation cashier training, and technology based distance learning cashier training programmes

The results obtained were analysed statistically using Pearson's Product-moment correlation and Bonferroni ttests. The empirical findings were used to draw conclusions and make recommendations regarding the research.

\section{Findings}

\section{Overall hypothesis}

The results of the ANOVA $F$ and the Bonferroni $t$ - test, rejected the null hypothesis in favour of the alternative hypothesis. It was found that significant differences in mean scores exist on four criteria: CM 3 General knowledge, CM 3 Encashment, CM 3 Procedures and Rules and OPM 3 Differences in cash in month 3.
The results of the ANOVA procedure Bonferroni $t$ - test are presented in Table 2 and 3. Only significant results are presented.

Table 2: Anova results

\begin{tabular}{|c|c|c|c|c|}
\hline & & df & $\mathbf{F}$ & Sig. \\
\hline \multirow[t]{3}{*}{ General } & Between Groups & 2 & 6,177 &, 003 \\
\hline & Within Groups & 107 & & \\
\hline & Total & 109 & & \\
\hline \multirow[t]{3}{*}{ CM 3 Deposit taking } & Between Groups & 2 & 9,064 &, 000 \\
\hline & Within Groups & 107 & & \\
\hline & Total & 109 & & \\
\hline \multirow[t]{3}{*}{ CM 3 Procedures \& } & Between Groups & 2 & 14,276 &, 000 \\
\hline & Within Groups & 107 & & \\
\hline & Total & 109 & & \\
\hline \multirow[t]{3}{*}{ OPM 3 Difference in } & Between Groups & 2 & 7,935 &, 001 \\
\hline & Within Groups & 107 & & \\
\hline & Total & 109 & & \\
\hline
\end{tabular}

\section{Sub-hypotheses}

The criteria selected to measure the effectiveness of the technology supported learning versus the more traditional methods were categorised into three groups: Supervisory ratings, Objective measures of performance, and objective measures of knowledge. Sub-hypotheses were set for each of these categories. Each of these categories will be discussed in detail below: 
Table 3: Results of the Bonferroni t-tests

\begin{tabular}{|c|c|c|c|c|c|c|c|c|}
\hline \multirow{2}{*}{\multicolumn{2}{|c|}{ Dependent Variable }} & \multirow{2}{*}{$\begin{array}{c}\text { (I) } \\
\text { Groups }\end{array}$} & \multirow{2}{*}{$\begin{array}{c}\text { (J) } \\
\text { Groups }\end{array}$} & \multirow{2}{*}{$\begin{array}{c}\text { Mean } \\
\text { Difference } \\
\text { (I-J) }\end{array}$} & \multirow{2}{*}{$\begin{array}{c}\text { Std. } \\
\text { Error }\end{array}$} & \multirow{2}{*}{ Sig. } & \multicolumn{2}{|c|}{ 95\% Confidence Interval } \\
\hline & & & & & & & Lower Bound & Upper Bound \\
\hline \multirow{13}{*}{ General knowledge } & \multirow{6}{*}{$\begin{array}{l}\text { Tukey's } \\
\text { LSD }\end{array}$} & \multirow{2}{*}{1} & 2 &,$- 93(*)$ & 27 & ,001 & $-1,46$ &,- 40 \\
\hline & & & 3 &,- 15 & 22 & ,498 &,- 59 & 29 \\
\hline & & \multirow{2}{*}{2} & 1 & ,93(*) & 27 & ,001 & 40 & 1,46 \\
\hline & & & 3 &, $78\left(^{*}\right)$ & ,28 & ,006 & ,23 & 1,33 \\
\hline & & \multirow{2}{*}{3} & 1 &, 15 & 22 & ,498 &,- 29 &, 59 \\
\hline & & & 2 &,$- 78(*)$ & ,28 &, 006 & $-1,33$ &,- 23 \\
\hline & \multirow{7}{*}{ Bonferroni } & \multirow{2}{*}{1} & 2 &,$- 93(*)$ & 27 & 002 & $-1,58$ &,- 28 \\
\hline & & & 3 &,- 15 & 22 & 1,000 &,- 69 & ,39 \\
\hline & & \multirow{2}{*}{2} & 1 & ,93(*) & 27 &, 002 & 28 & 1,58 \\
\hline & & & 3 &, $78(*)$ & ,28 &, 019 & $9,98 \mathrm{E}-02$ & 1,46 \\
\hline & & \multirow{3}{*}{3} & 1 & ,15 & 22 & 1,000 &,- 39 & ,69 \\
\hline & & & 2 &,$- 78(*)$ & 28 & ,019 & $-1,46$ & $-9,98 \mathrm{E}-02$ \\
\hline & & & 2 &,- 70 &, 34 &, 126 & $-1,53$ &, 13 \\
\hline \multirow{12}{*}{ Encashment } & \multirow{6}{*}{$\begin{array}{l}\text { Tukeys } \\
\text { LSD }\end{array}$} & \multirow{2}{*}{1} & 2 &,$- 72(*)$ & ,23 &, 002 & $-1,17$ &,- 27 \\
\hline & & & 3 &,$- 72\left(^{*}\right)$ &, 19 &, 000 & $-1,09$ &,- 34 \\
\hline & & 2 & 1 &, $72(*)$ & ,23 & ,002 &, 27 & 1,17 \\
\hline & & 2 & 3 & $3,66 \mathrm{E}-03$ &, 24 & ,988 &,- 47 &, 48 \\
\hline & & 3 & 1 &, $72(*)$ &, 19 &, 000 &, 34 & 1,09 \\
\hline & & & 2 & $-3,66 \mathrm{E}-03$ & ,24 & ,988 &,- 48 &, 47 \\
\hline & & 1 & 2 &,$- 72\left(^{*}\right)$ & ,23 & ,006 & $-1,28$ &,- 16 \\
\hline & & 1 & 3 &,$- 72(*)$ & ,19 & ,001 & $-1,17$ &,- 26 \\
\hline & Bonferroni & 2 & 1 &, $72(*)$ &, 23 &, 006 &, 16 & 1,28 \\
\hline & Domlitilomiti & 2 & 3 & $3,66 \mathrm{E}-03$ & ,24 & 1,000 &,- 58 &, 58 \\
\hline & & 3 & 1 &, $72(*)$ &, 19 &, 001 &, 26 & 1,17 \\
\hline & & 3 & 2 & $-3,66 \mathrm{E}-03$ & 24 & 1,000 &,- 58 & ,58 \\
\hline & & 1 & 2 & $-1,32\left(^{*}\right)$ &, 25 &, 000 & $-1,81$ &,- 83 \\
\hline & & 1 & 3 &,- 30 & ,20 & ,140 &,- 71 & ,10 \\
\hline & Tukey’s & 2 & 1 & $1,32(*)$ &, 25 &, 000 &, 83 & 1,81 \\
\hline & LSD & 2 & 3 & $1,02(*)$ & ,26 &, 000 &, 51 & 1,53 \\
\hline & & 3 & 1 &, 30 & 20 &, 140 &,- 10 &, 71 \\
\hline & & 3 & 2 & $-1,02\left(^{*}\right)$ & ,26 &, 000 & $-1,53$ &,- 51 \\
\hline Procedures \& Rules & & 1 & 2 & $-1,32\left(^{*}\right)$ &, 25 &, 000 & $-1,93$ &,- 72 \\
\hline & & 1 & 3 &,- 30 &, 20 & ,419 &,- 80 & , 19 \\
\hline & Bonferroni & 2 & 1 & $1,32\left(^{*}\right)$ &, 25 &, 000 &, 72 & 1,93 \\
\hline & Bonterrone & 2 & 3 & $1,02\left(^{*}\right)$ & ,26 & ,000 & ,39 & 1,65 \\
\hline & & 3 & 1 & , 30 & ,20 & ,419 &,- 19 & ,80 \\
\hline & & 3 & 2 & $-1,02(*)$ &, 26 &, 000 & $-1,65$ &,- 39 \\
\hline & & 1 & 2 & 16,73 & 79,09 &, 833 & $-140,05$ & 173,51 \\
\hline & & 1 & 3 & $-236,20(*)$ & 64,98 &, 000 & $-365,00$ & $-107,39$ \\
\hline & Tukey's & 2 & 1 & $-16,73$ & 79,09 &, 833 & $-173,51$ & 140,05 \\
\hline & LSD & & 3 & $-252,93(*)$ & 82,32 &, 003 & $-416,12$ & $-89,74$ \\
\hline & & 3 & 1 & $236,20\left(^{*}\right)$ & 64,98 &, 000 & 107,39 & 365,00 \\
\hline & & & 2 & $252,93(*)$ & 82,32 &, 003 & 89,74 & 416,12 \\
\hline Differences after 3 months & & 1 & 2 & 16,73 & 79,09 & 1,000 & $-175,62$ & 209,09 \\
\hline & & & 3 & $-236,20(*)$ & 64,98 &, 001 & $-394,23$ & $-78,17$ \\
\hline & & 2 & 1 & $-16,73$ & 79,09 & 1,000 & $-209,09$ & 175,62 \\
\hline & Bonferroni & 2 & 3 & $-252,93(*)$ & 82,32 &, 008 & $-453,15$ & $-52,71$ \\
\hline * The mean difference is & & & 1 & $236,20(*)$ & 64,98 & 001 & 78,17 & 394,23 \\
\hline significant at the, 05 level. & & 3 & 2 & $252,93(*)$ & 82,32 &, 008 & 52,71 & 453,15 \\
\hline & & & 2 &,- 60 & 45 & ,547 & $-1,69$ & ,49 \\
\hline
\end{tabular}




\section{Supervisory ratings}

Six measures were used in this category - cash handling and balancing skills (immediately after training), and deposit taking, encashment (cash handling), procedures and rules and general independent functioning (three months after training).
No significant differences in means on any of the six measures for the three types of training were found using ANOVA and the Tukey and Bonferroni $t$-tests. Thus the null hypothesis is accepted. A summary of the findings is presented in table 4 .

Table 4: Correlations between supervisory ratings and knowledge tests

\begin{tabular}{l|c|c|c|c}
\hline \multicolumn{1}{c|}{ Variable } & $\begin{array}{c}\text { CM 3 general } \\
\text { knowledge }\end{array}$ & $\begin{array}{c}\text { CM 3 deposit taking } \\
\text { knowledge }\end{array}$ & $\begin{array}{c}\text { CM 3 encashment } \\
\text { knowledge }\end{array}$ & $\begin{array}{c}\text { CM 3 proceedures and } \\
\text { rules }\end{array}$ \\
\hline $\begin{array}{l}\text { SR 3 general independent } \\
\text { functioning }\end{array}$ & $\begin{array}{c}-, 074 \\
\mathrm{p}=, 44\end{array}$ & & & \\
\hline SR 3 deposit taking skill & & 0,328 & \\
& & $\mathrm{p}=0,00$ & & \\
\hline SR 3 encashment & & & 0,403 & \\
Skill & & & $\mathrm{p}=0,00$ & \\
\hline SR 3 procedures and rules & & & & 0,285 \\
Skills & & & $\mathrm{p}=0,003$ \\
\hline
\end{tabular}

Pearson's Product-Moment Correlations

Marked correlations are significant at $\mathrm{p}>0,05$

This finding has significant implications for learning and development and requires further discussion. First, the finding does not support many of the claims made in the literature that TBDL results in 'observed improvement in performance'. An argument could be put forward that one factor which may have had an influence on the results is supervisors' inability to rate employees' performance accurately. However, two sets of information counter this proposition: First, the use of a behaviourally anchored rating scale minimises the impact of rater bias and the central tendency (Smith \& Kendall, 1963). Second, the statistically significant, high negative correlations between supervisory ratings on deposit taking $(\mathrm{r}=-, 68, \mathrm{p}<0,00)$ and encashment skills $(\mathrm{r}=-0,68, \mathrm{p}<0,00)$ and knowledge of rules and procedures $(r=0,50, p<0,00)$ indicate that, in general, high supervisory ratings are associated with low losses (as a result of making errors). Thus, there is convergence between objective measures of performance and supervisors' ratings.

A more plausible explanation is that most of the reported increases in observable performance is based on case studies and not on empirical research (Corporate Leadership Council, 2000 \& 2001). The technology based learning systems implementations reported on in the literature were mostly done in information technology sector companies such as IBM, Dell, Cisco and reported managements' perceptions about improvements in employees' performance (Author unknown, 2001; Carozza, 2000; Corporate Leadership Council, 2000 \& 2001).

A further analysis of correlations between supervisory ratings and scores on the competence tests reveal that a significant positive correlation (with the exception of the 'CM 3 General Knowledge - SR 3 General independent functioning' pairing) exists between the score on the test of knowledge and the supervisory rating of skill in the area. However, the relatively low values of these correlations indicate that the possession of knowledge does not necessarily translate into skill or appropriate behaviour. This insight is further supported by much higher correlations between the objective performance measure (Differences in cashiers' cash in month 3) and supervisors' ratings of skill on the three dimensions of deposit taking skill $(\mathrm{r}=-0,68$, $\mathrm{p}<0,00)$, encashment $(\mathrm{r}=-0,68, \mathrm{p}<0,00)$, and knowledge of rules and procedures $(\mathrm{r}=-0,49, \mathrm{p}<0,00)$. Here, observed 'correct' behaviour as measured by supervisory ratings translated into fewer errors.

The low correlation between the supervisory rating of independent functioning ('SR3 General Independent Functioning') which is an integrative measure of performance, and the underlying knowledge components could not be explained except to assume other factors, such as personality, cognitive ability and prior work experience may have had an influence on the way in which people performed on the job. Barret and Depinet (1991) conducted a meta-analytic study of research in which academic achievement (grades) was used to predict occupational success. The results of this study show a relationship between academic performance and occupational success, which may stem from underlying associations between academic performance and intellectual ability, motivation, and attitudes toward work. Hunter (1986) supports this possibility by demonstrating that higher ability equates to better performance. This relationship has also been found at varying educational levels, such as medical school graduates, MBAs, college graduates, and high school graduates in the USA (Barret \& Depinet, 1991).

\section{Objective measures of performance}

Two criteria were used - the absolute value of differences in cashiers cash in the month following training, and the same rating for month 3 after training. The measure is constructed by taking the sum total differences per cashier for the month - thus it comprises the absolute value of surpluses and deficits for the month. Many reasons could result in a surplus or deficit position, however, most of these are addressed in the training programmes making it a good composite measure of the effectiveness of the training. 
In the first month immediately after training, no differences in means exist. However, the differences become significant over time - that is, the results from measures taken in month three (OPM 3 DIFF) indicate significant differences in means.

Significant differences for the measures taken in month 3 were found in means between the TBDL training and traditional classroom, as well as between traditional classroom training with simulated learning and traditional classroom. No difference was found between classroom with simulated learning and TBDL.

Consequently the null hypothesis was partially rejected in favour of the alternative hypothesis:

For objective performance ratings, significant differences in means exist between classroom-based cashier training, classroom-based \& simulation cashier training and technology based distance learning cashier training programmes.

The finding that there are no significant differences in means on the objective performance measure (OPM I DIFF) taken immediately after the training supports the notion that skilled application of knowledge develops over time through practice (Fritz, 1997; Galagan, 2000; O’Driscoll, Humphries \& Larsen, 1991) and is not 'taught' (Shirley \& Wheeler, 1995).

Additionally it was noted that apart from the correlation between the supervisory ratings and the 'OPM 3 DIFF' measure, discussed under Supervisory ratings, a significant correlation exists between 'OPM I DIFF' and 'OPM 3 DIFF' $(r=0,43, p<0,00)$. This moderate correlation may indicate that selection related issues could be a confounding variable - that is that a group of employees, no matter the type and quality of training given, may never function optimally as a result of a poor person-job fit.

\section{Objective measures of knowledge}

Five criteria were designed and used to measure knowledge:

Table 5: Criteria to measure knowledge

\begin{tabular}{l|l}
\hline \multicolumn{1}{c|}{ Measure } & \multicolumn{1}{c}{ Abbreviation } \\
\hline CM I Post course exam (theory) & CMIpostc \\
\hline CM 3 General knowledge & CM3Gener \\
\hline CM 3 Deposit taking & CM3Depos \\
\hline CM 3 Encashment & CM3Encas \\
\hline CM 3 Procedures \& Rules & CM3Proce \\
\hline
\end{tabular}

One measure, 'CM I Post course exam (theory)' was obtained immediately after the completion of the various training courses. The remainder of measures were obtained three months after the initial training had been completed. Significant differences in means were found in three of the variables: 'CM 3 General knowledge', 'CM 3 Encashment', 'CM 3 Procedures \& Rules'.

Consequently the null hypothesis was rejected in favour of the alternative hypothesis:

For scores achieved on competence tests significant differences in means exist between classroom-based cashier training, classroom-based and simulation cashier training, and technology based distance learning cashier-training programmes

\section{CM3 general knowledge}

The classroom and simulation programme obtained the highest mean score on the 'CM3 General Knowledge' dimension. A number of factors could have contributed to this result - the most likely reason being the structured nature of the simulated session, where most of the challenging situations are covered systematically. On the TBDL programme, it depends on the on-site facilitator to show and explain these permutations to learners. This contradicts some of the claims made in the literature of high knowledge acquisition and retention rates achieved through technology supported learning systems.

\section{3 encashments}

No differences in means between the classroom and classroom and simulation based learning systems were observed on the 'CM3 Encashments' dimension, however, both these two methods have significantly different means to the TBDL programme, with the latter the lowest of the three,

Again, this finding is contrary to the general statements made in the literature, but as stated before, these statements were not empirically derived or verified, but were obtained from management or were implementation case studies.

\section{CM3 procedures and rules}

With the 'CM3 Procedures and Rules' dimension, no differences in means were found between TSDL and traditional classroom training, but both were significantly different to classroom and simulation type training. This finding could be attributed to the structured nature of the classroom and simulation type training - on site facilitators may omit to follow the on-the-job facilitation guidelines consistently. Also, time pressures may not permit the same amount of on-the-job practice, as learners would be exposed to during the classroom and simulation type learning programme.

All the findings are summarised and presented in Table 6 . 
Table 6: Summary of findings

\begin{tabular}{|c|c|c|c|c|}
\hline \multicolumn{2}{|c|}{ Criteria } & TBDL & Classroom \& Simulation & Classroom \\
\hline \multirow[t]{6}{*}{ Supervisory ratings } & SR I Balancing & \multirow{6}{*}{\multicolumn{2}{|c|}{ ND }} & \\
\hline & SR I Cash Handing skills & & & \\
\hline & SR 3 Deposit taking skills & & & \\
\hline & SR 3 Encashment skills & & & \\
\hline & SR 3 Procedure and rule adherence & & & \\
\hline & SR 3 General independent functioning & & & \\
\hline \multirow{2}{*}{ Objective performance measures } & OPM I Differences in cashiers cash & \multirow{2}{*}{\multicolumn{2}{|c|}{$\begin{array}{l}\mathrm{ND} \\
\mathrm{H}\end{array}$}} & \\
\hline & OPM 3 Differences in cashiers cash & & & $\mathrm{L}$ \\
\hline \multirow{5}{*}{ Knowledge measures } & CM I Post course evaluation & & & \\
\hline & CM 3 General Knowledge & $\mathrm{L}$ & $\mathrm{H}$ & $\mathrm{L}$ \\
\hline & CM 3 Deposit Taking Knowledge & \multicolumn{2}{|l|}{ ND } & \\
\hline & CM 3 Encashment knowledge & $\mathrm{L}$ & $\mathrm{H}$ & $\mathrm{H}$ \\
\hline & CM 3 Procedures and rules knowledge & $\mathrm{H}$ & $\mathrm{H}$ & $\mathrm{L}$ \\
\hline
\end{tabular}

Key: $\quad$ ND no statistical difference in means observed

$\mathrm{H}$ : statistically significant difference in means, high means/group

L: statistically significant difference in means, low means/group

The analysis of the data and statistical results resulted in a number of additional insights and findings:

- No significant differences in means were found among any of the measures taken immediately after the training took place;

- No significant differences in means between the three methods of instruction and learning were found among the 'supervisors' ratings'

- High scores on knowledge and knowledge retention did not translate into fewer errors.

These secondary findings hold implications for learning and development.

First, supervisory ratings are often used as dependent variables in studies of training effectiveness. This investigation has highlighted the shortcomings of this measure.

Further, studies of learning effectiveness typically use knowledge tests scores as an indicator of whether learning has taken place. Again, the results indicate that 'having knowledge' does not necessarily translate into performing on the job.

Finally, the finding that no differences in means exist on any of the measures taken immediately after training took place indicates that learning take place over time with practice.

\section{Limitations of the study and recommendations for future research}

The study has a number of limitations. The major limitation is the fact that it was conducted in one organisation only. Jenks (1991) argues, however, that this should not seen as a problem as the issue of job success is essentially organisationally bound, and the results of one study would therefore not necessarily be generalisable to other organisations.

A further limitation is the design of the study, which was influenced by organisational constraints. It was not possible to draw a random sample from the population of eligible staff, and the sample was constructed on the basis of nominations for training. Second, it was not possible to control for biographical variables, such as language, age, length of service and the duration of prior experience.

A third, and major, limitation was the impact and influence subjects' immediate supervisors might have had on their job success. It was not possible to control for the amount of individual mentoring and coaching a subject may have received, and the impact that this could have had on his or her success over the three-month period.

Further, the culture fairness of the learning intervention that is familiarity with banking concepts and constructs, technology and English as medium of instruction could also be questioned.

Notwithstanding the caveats raised, the research reported in this article is of considerable theoretical and heuristic value. It demonstrates clearly that the terms 'learning and learning systems' are multidimensional in the sense that success depends on multiple factors - the learning system, the organisational context and individual factors such as ability and temperament.

\section{Conclusion}

The results of the study did not fully support the claims made in the literature of the superiority of a Technology Based Distance Learning approach. The benefits of such approaches are mainly found in the efficiencies - lower cost, better scalability (ability to train many or few people at the same time without physical constraints such as facilitators or premises). 
On the balance, however, it seems that simulation based classroom training resulted in the best transfer and retention of knowledge, although this did not translate into significantly better performance ratings as measured by supervisors, nor did it result in fewer (costly) mistakes when performing their duties.

The fact that no significant difference was found between the TBDL approach and the classroom and simulation system is particularly encouraging. The underlying construction of the approaches (from an adult learning/ instruction perspective) is very similar - both programme structures combine the theoretical knowledge transfer and skills building into one integrated learning experience. These programmes differ in terms of method of delivery the technology supporting TBDL model is a far more cost efficient offering. For example, this could be seen in that the TBDL programme is presented over two days only, as opposed to the 5 days of the classroom and simulation based course. This equates to a saving of $60 \%$ in time, which could be directly translated into a cost saving.

Finally it was shown that all of the methods have shortcomings. It is suggested that a combination of classroom and technology based distance learning would be the best solution and that it occurs over a period of time.

The generalisability of the results is limited because the study was done in one organisation. It is important to establish the extent to which organisational culture may have influenced the results. A further study could compare findings between different organisations in the financial services industry. It would be both interesting and useful to repeat the study at other levels other than cashier, such as middle and senior managerial levels, to determine whether the findings concur.

\section{References}

Akkerman, A. 1989. 'Criteria and individual assessment'. In Smith, M. \& Robertson, I. (Eds.). Advances in selection and assessment. Chichester: Wiley.

Dell Computers, 2001. 'Dell learning', [online] URL: http://www.dell.com. Accessed on 22 January 2001.

Forbes Magazine, 15 December 2000. 'E-learning', [online] URL: http://www.forbes.com/specialsections/elearning/.

Barrett, G.V. \& Depinet, R.L. 1991. 'A reconsideration of testing for competence rather than for intelligence', American Psychologist, 46: 1012-1024.

Bassi, L.J., Benson, G. \& Cheney, S. 1996. 'The top ten trends', Training \& Development, November: 28-42.

Carozza, T. 2000. 'From hyperlinks to human links at Hewlett-Packard', Knowledge Management Review, 3(3): 16-24.

Chamberlain, G. 1997. 'Skills: How to develop a system for on the job training', Productivity SA. March/April: 15-18.
Corporate Leadership Council. 2000. Reskilling for the agile enterprise. Washington: Corporate Executive Board.

Corporate Leadership Council. 2001. Reskilling for the agile enterprise. Washington: Corporate Executive Board.

Egan, M. \& Kim, J. 2000. 'Knowledge sharing at the World Bank', Knowledge Management Review, 3(3): 7-14.

Eager, M. 1999. 'Building a learning/knowledge organisation: Discussion document'. Unpublished document.

Fritz, M. 1997. 'Is web-based training new hype in old wineskins?', Emedia Professional, June: 69-71.

Galagan, P.A. 2000. 'The e-learning revolution', Training and Development, 54(12): 24-30.

Hamel, G. 2000. 'Waking up IBM - how a gang of unlikely rebels transformed the big blue', Harvard Business Review, July - August: 137-145.

Hunter, J.E. 1986. 'Cognitive ability, cognitive aptitudes, job knowledge and job performance', Journal of Vocational Behavior, 29: 340-362.

Jenks, M.R. 1991. 'The identification of management potential'. Unpublished Masters dissertation. Johannesburg: University of the Witwatersrand.

Johnson, R.A. \& Wichern, D.W. 1997. Business statistics. Decision making with data. New York: Wiley.

Jouvancy, A. 2001. 'The ABC of E-learning', Le Monde Interactif, 4 January.

Landy, F.J. \& Rastegary, H. 1989. 'Criteria for selection: Personnel selection methods.' In Smith, M. \& Robertson, I.T. (Eds.). Advances in selection and assessment. Chichester: Wiley.

O’Driscoll, M.P., Humphries, M. \& Larsen, H.H. 1991. 'Managerial activities, competence and effectiveness: Manager and subordinate perceptions', The International Journal of Human Resource Management, 2(3): 313-326.

Shirley, D. \& Wheeler, R. 1995. 'Potential and competencies'. Unpublished manuscript: Personnel Assessment Department, Standard Bank of South Africa.

Smith, P.C. \& Kendall, L.M. 1963. 'Retranslation of expectations: An approach to the construction of unambiguous anchors for rating scales', Journal of Applied Psychology, 47: 149-155.

\section{Acknowledgement}

The authors would like to thank Peter Fridjhon, School of Statistics and Actuarial Science, University of the Witwatersrand for guidance with the statistical analysis. 